\title{
Factors associated with clinical deterioration shortly after PE
}

\author{
Christopher Kabrhel, ${ }^{1}$ Ikenna Okechukwu, ${ }^{1}$ Praveen Hariharan, ${ }^{1}$ \\ James Kimo Takayesu, ${ }^{1}$ Peter MacMahon, ${ }^{2}$ Faris Haddad, ${ }^{3}$ Yuchiao Chang ${ }^{4}$
}

- Additional material is published online only. To view please visit the journal online (http://dx.doi.org/10.1136/ thoraxjnl-2013-204762)

${ }^{1}$ Department of Emergency Medicine, Center for Vascular Emergencies, Massachusetts General Hospital, Harvard Medical School, Boston, Massachusetts, USA ${ }^{2}$ Department of Radiology, Mater Misericordiae University Hospital, Dublin, Ireland ${ }^{3}$ Department of Radiology, Inova Fairfax Hospital, Falls Church, Virginia, USA ${ }^{4}$ Department of Medicine, Massachusetts General Hospital, Harvard Medical School, Boston, Massachusetts, USA

\section{Correspondence to Dr Christopher Kabrhel, Center for Vascular Emergencies, Department of Emergency Medicine, Massachusetts General Hospital, Zero Emerson Place, Suite 3B, Boston, MA 02114, USA; \\ ckabrhel@partners.org}

International Society of Thrombosis and Hemostasis, Amsterdam, 2013, Society of Academic Emergency Medicine, Denver, CO 2012.

Received 29 October 2013 Revised 28 April 2014 Accepted 2 May 2014 Published Online First 20 May 2014

\footnotetext{
To cite: Kabrhel $C$, Okechukwu I, Hariharan P, et al. Thorax 2014;69: 835-842.
}

\begin{abstract}
Background Several factors have been associated with mortality in the months after PE. Factors associated with short-term clinical deterioration or need for hospitalbased intervention are less well known.

Methods We prospectively enrolled consecutive emergency department patients with PE and recorded clinical, biomarker and radiographic data. We assessed hospitalised patients daily to identify clinical deterioration or need for hospital-based intervention for 5 days after PE. We captured postdischarge events via 5-day and 30-day interviews. We used univariate and multivariable models to assess associations with clinical deterioration, severe clinical deterioration and 30-day allcause mortality. We also assessed the test characteristics of three published clinical decision rules.

Results We enrolled 298 patients with PE: mean age 59 (SD \pm 17$)$ years; $152(51 \%)$ male and $268(90 \%)$ white race. 101 (34\%) patients clinically deteriorated or required a hospital-based intervention within 5 days, and 197 (66\%) did not. 27 (9\%) patients suffered severe clinical deterioration and 12 died within 30 days. Factors independently associated with clinical deterioration were

\section{Key messages}

What is the key question?

- How many patients with PE clinically deteriorate or otherwise need hospitalisation immediately after their diagnosis, and can we identify these patients?

\section{What is the bottom line?}

- Most patients with PE do not clinically deteriorate or require a hospital-based intervention after their diagnosis, and while several factors are associated with clinical deterioration, existing clinical prediction rules have limited accuracy.

\section{Why read on?}

- By following patients every day for 5 days after their $\mathrm{PE}$, this study provides highly granular data on outcomes related to PE occurring during the time patients are usually in the hospital.
\end{abstract} hypotension ( $p=0.001)$, hypoxia $(p<0.001)$, coronary disease $(p=0.004)$, residual deep vein thrombosis $(p=0.006)$ and right heart strain on echocardiogram $(p<0.001)$. In contrast, factors associated with 30-day all-cause mortality were active malignancy $(p<0.001)$ and congestive heart failure $(p=0.009)$. The sensitivity of clinical decision rules was moderate (39-80\%) for 5-day clinical deterioration but higher (67-100\%) for 30-day mortality.

Conclusions Most patients do not clinically deteriorate after PE diagnosis. Several factors are associated with short-term clinical deterioration, but these factors differ from those associated with 30-day mortality.

\section{INTRODUCTION}

Outcomes after pulmonary embolism (PE) vary widely. For some patients, PE causes rapid hemodynamic collapse, whereas for others, PE is clinically inconsequential. Identifying patients at risk for short-term clinical deterioration is important and challenging. Increasingly, physicians must determine which patients with $\mathrm{PE}$ should be admitted to a hospital floor or an intensive care setting and which patients are safe for discharge from the emergency department (ED).

Several factors are associated with mortality and recurrence in the months after PE, and clinical decision rules (CDRs) have been developed to quantify these risks. ${ }^{1-12}$ Validation studies and a large clinical trial of outpatient PE treatment have demonstrated a low incidence of death or recurrent PE within 30-90 days in patients with low CDR scores. ${ }^{1} 81011$ 13-18 ${ }^{18}$ However, these outcomes may not adequately inform the decision to admit or discharge a patient from the ED. A typical hospitalisation for PE lasts 3-5 days. Clinicians consider events during this timeframe more important to the disposition decision than events occurring after a patient would be discharged from the hospital. ${ }^{19} 20$ Also, mortality after PE is frequently due to underlying illness. ${ }^{15} 1819$ The inclusion of 'host factors' like malignancy and cardiopulmonary disease in CDRs may inflate their association with all-cause mortality.

Identifying factors associated with patient-oriented outcomes occurring during a typical PE hospitalisation may help clinicians decide which patients benefit from inpatient admission. We therefore performed this study with three goals in mind: (A) to determine the incidence of clinical deterioration or the need for hospital-based intervention occurring during a typical hospitalisation for PE; (B) to identify factors associated with these events, and $(C)$ to determine whether CDRs identify patients at risk for these events. To the authors' knowledge, this is the first 
prospective study of factors associated with a wide spectrum of clinical events, occurring in the timeframe of a typical hospitalisation for PE.

\section{METHODS \\ Design}

We performed a prospective non-interventional study of consecutive adult ED patients diagnosed with PE between October 2008 and December 2011 in accordance with standards for the reporting of observational studies (STROBE) and best practices. ${ }^{21}$ The study was approved by the Human Research Committee of Partners HealthCare (2008-P-002001). All patients provided written informed consent.

\section{Setting}

Massachusetts General Hospital is an urban, university hospital with an annual ED volume of 95000 patient visits.

\section{Subject eligibility and enrolment}

We used a combination of active screening and review of radiologic tests to identify patients eligible for enrolment, which allowed us to enrol consecutive patients 6 days a week (except Saturday). We enrolled adult (age $>17$ years) patients diagnosed with radiographically proven $\mathrm{PE}$ in the ED. Radiographically proven PE was defined as (A) a filling defect in a pulmonary artery on computed tomography pulmonary angiogram (CTPA); (B) a high-probability ventilation/perfusion scan and (C) a positive leg ultrasound or CT venogram performed to diagnose PE (not isolated deep vein thrombosis (DVT)), confirmed by the treating clinician. PE diagnoses were based on the interpretation of board-certified radiologists not affiliated with the study. CTPA were re-read by two board-certified radiologists affiliated with the study to confirm and quantify PE.

Patients were eligible if PE was diagnosed within $24 \mathrm{~h}$ of ED registration. Patients transferred from outside EDs or clinics with a diagnosis of PE were eligible until $24 \mathrm{~h}$ after confirmatory imaging. Patients with PE found incidentally (ie, without clinical suspicion) were eligible. Patients were excluded if they were $<18$ years old, could not provide informed consent or were unable to follow-up. Patients diagnosed with PE $>24 \mathrm{~h}$ after ED registration were excluded.

\section{Data collection and follow-up}

After enrolment, outcomes associated with PE were identified prospectively. Study staff interviewed each patient, their nurses and reviewed the medical record every day for 5 days to identify clinical deterioration events. Five days is consistent with the median length of stay for PE in our institution as well as the timeframe cited as most relevant to the disposition of a patient with PE in a survey of clinicians. ${ }^{20} 2223$

We performed postdischarge follow-up using a validated combination of telephone calls and electronic medical record review. ${ }^{24}$ On days 5 and 30, we called discharged patients to ask whether they had returned to an ED or clinic for any unscheduled visits and whether a visit was related to recurrent PE or bleeding.

\section{Independent variables}

At the time of enrolment, we recorded clinical factors including demographics, ED vital signs and comorbid illness via direct patient interview and confirmed these by review of each patient's electronic medical history/problem list (see online supplement for detailed variable definitions). Discrepancies were adjudicated by two study investigators (CK, IO or $\mathrm{PH})$, with ties broken by a third investigator. To standardise data collection and reduce confounding while capturing results potentially available to an emergency physician, we chose a priori to record radiological, echocardiographic and biomarker results that were available within $24 \mathrm{~h}$ of PE diagnosis. Radiological studies and biomarkers were performed at the discretion of the treating physician. However, we also collected blood samples at the time of enrolment and used these to complete biomarker analyses when necessary.

We gathered data required to calculate three published CDRs: the pulmonary embolism severity index (PESI), ${ }^{8}$ the simplified PESI (sPESI), ${ }^{12}$ and the Geneva Prognostic Rule. ${ }^{3}$ As arterial blood gasses are not routinely performed after PE in our institution, we modified the Geneva Prognostic Rule by substituting oxygen saturation ( $\mathrm{Sa02}$ ) $<90 \%$ measured by pulse oximetry for partial pressure of oxygen in arterial blood $\left(\mathrm{PaO}_{2}\right)$ $<8 \mathrm{kPa}^{35}$

\section{Outcomes}

Outcome events were collected after patients were discharged from the ED to the inpatient setting or home. Our primary outcome was designed to include a wide spectrum of clinical deterioration events and interventions that typically require hospitalisation (table 1). We also assessed severe clinical deterioration, defined as an inherently unstable condition or advanced intervention/therapy. Lastly, we assessed all-cause 30-day mortality to facilitate comparison with previous studies. We felt that the variables associated with events secondary to PE were likely to be different than the variables associated with events secondary to treatment, so we did not include bleeding in our primary outcome but did include it in a secondary analysis.

\section{Statistical analysis}

Demographics were summarised using mean and SD for continuous variables and percentages for categorical variables. We performed $\chi^{2}$ tests to identify univariate associations and multivariable logistic regression to identify factors independently associated with clinical deterioration, severe deterioration and 30-day mortality. Univariate analysis was performed on all variables potentially clinically related to adverse outcomes after PE and variables with $p$ values $<0.2$ were considered potential predictors for the models. Final models included variables significant at the 0.05 level. Threshold values for continuous measures were based on previous PE literature or, when no accepted threshold was available in the literature (eg, N-terminal brain natriuretic peptide (NT-proBNP)), from exploratory data analysis for choosing optimal cutpoints.

Based on published studies, we defined low risk as PESI categories I-II, sPESI $<1$ point and Geneva Prognostic Rule $\leq 2$ points. ${ }^{3} 91012$ For each CDR, we performed receiver operating characteristic (ROC) curve analysis, calculated sensitivity, specificity, positive (PPV) and negative predictive value (NPV), and positive/negative likelihood ratios with 95\% CIs. PPV and NPV were calculated based on the outcome prevalence in our study sample. We performed a subanalysis of CDR performance excluding patients with a shock index (pulse rate/systolic blood pressure) $\geq 1$ in the ED. All analyses were done using SAS V.9.3 (The SAS Institute, Inc., Cary, North Carolina, USA). Two-sided $\mathrm{p}<0.05$ was considered as statistical significance.

\section{RESULTS}

We identified 403 patients with PE in the ED and enrolled 301 (figure 1). After enrolment, three patients were deemed ineligible: two because PE was diagnosed $>24 \mathrm{~h}$ before enrolment, 
Table 1 Outcome definitions

\begin{tabular}{|c|c|}
\hline Any patient who & Definition \\
\hline \multicolumn{2}{|l|}{ Primary outcome } \\
\hline Received advanced cardiac life support & $\begin{array}{l}\text { Cardiopulmonary resuscitation, defibrillation or treatment with bolus doses of epinephrine, atropine or } \\
\text { vasopressin }\end{array}$ \\
\hline Developed a new cardiac dysrhythmia & $\begin{array}{l}\text { Atrial fibrillation or flutter, ventricular tachycardia or fibrillation not present on the patient's emergency } \\
\text { department electrocardiogram }\end{array}$ \\
\hline $\begin{array}{l}\text { Developed hypoxaemia }\left(\mathrm{SaO}_{2}<90 \%\right) \text { or required } \\
\text { respiratory support }(>2 \mathrm{~L} \text { by nasal cannula) }\end{array}$ & $\begin{array}{l}\text { Hypoxaemia is defined as an oxygen saturation }<90 \% \text { measured by pulse oximetry regardless of the use of } \\
\text { supplemental oxygen } \\
\text { Respiratory support is defined as treatment with }>2 \mathrm{~L} / \mathrm{min} \text { of oxygen by nasal cannula, non-rebreather mask } \\
\text { or any positive pressure ventilation including endotracheal intubation }\end{array}$ \\
\hline $\begin{array}{l}\text { Developed hypotension (systolic blood pressure } \\
<90 \mathrm{~mm} \mathrm{Hg} \text { ) }\end{array}$ & Systolic blood pressure $<100 \mathrm{~mm} \mathrm{Hg}$ on two consecutive measurements $>15 \mathrm{~min}$ apart \\
\hline Was treated with vasopressors & Any continuous infusion of dopamine, norepinephrine or epinephrine \\
\hline Underwent thrombolysis or thrombectomy & Thrombolysis or thrombectomy includes any treatment with tPA (activase), catheter or surgical thrombectomy \\
\hline Developed recurrent PE & A new filling defect on repeat radiological examination \\
\hline Died & Death from any cause \\
\hline \multicolumn{2}{|l|}{ Severe outcome } \\
\hline Received advanced cardiac life support & $\begin{array}{l}\text { Cardiopulmonary resuscitation, defibrillation or treatment with bolus doses of epinephrine, atropine or } \\
\text { vasopressin }\end{array}$ \\
\hline Developed ventricular tachycardia or fibrillation & Ventricular tachycardia or fibrillation not present on the patient's emergency department electrocardiogram \\
\hline $\begin{array}{l}\text { Required positive pressure ventilation or endotracheal } \\
\text { intubation }\end{array}$ & $\begin{array}{l}\text { Respiratory support using positive pressure ventilation, such as CPAP, biphasic positive airway pressure } \\
\text { (BiPAP) or endotracheal intubation }\end{array}$ \\
\hline Was treated with vasopressors & Any continuous infusion of dopamine, norepinephrine or epinephrine \\
\hline Underwent thrombolysis or thrombectomy & Thrombolysis or thrombectomy includes any treatment with tPA (activase), catheter or surgical thrombectomy \\
\hline Died & Death from any cause \\
\hline
\end{tabular}

and one because the CTPA was re-read as tumour, not PE. We included 298 patients in our final analysis.

Demographics and comorbidities are presented in table 2 . Diagnostic testing included CTPA (288/298, 96.6\%), V/Q (5/298, $1.7 \%)$, lower extremity ultrasound (99/298, 33.2\%), CT venography $(136 / 298,45.6 \%)$, echocardiography $(66 / 298$, $22.1 \%)$, troponin $(289 / 298,97.0 \%)$, NT-proBNP $(270 / 298$, 90.6\%) and D-dimer (272/298, 91.3\%). Most patients (250, $84 \%)$ were admitted to hospital floors, with 24 (8\%) admitted to intensive care units and $23(8 \%)$ to an ED observation unit. PE
Figure 1 Eligible and enrolled patients.

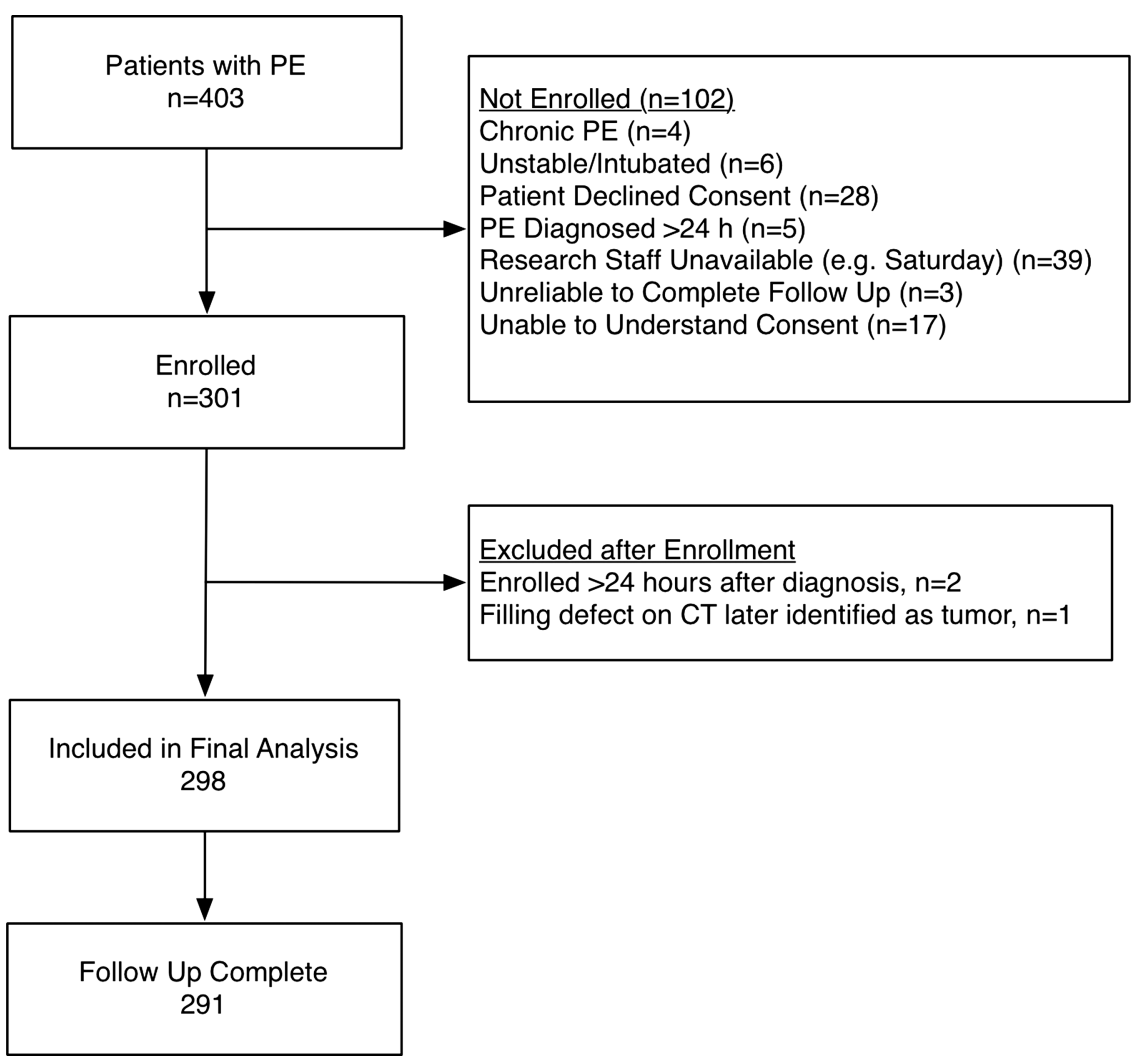


Table 2 Demographics of analysed patients

\begin{tabular}{|c|c|c|}
\hline Demographics & \multicolumn{2}{|l|}{$\mathbf{n}$} \\
\hline Enrolled & \multicolumn{2}{|l|}{298} \\
\hline Age (mean, SD) & 59 & 17 \\
\hline Male & 152 & $51 \%$ \\
\hline \multicolumn{3}{|l|}{ Race } \\
\hline White & 268 & $90 \%$ \\
\hline Black & 18 & $6 \%$ \\
\hline Other & 12 & $4 \%$ \\
\hline \multicolumn{3}{|l|}{ Ethnicity } \\
\hline Non-Hispanic & 290 & $97 \%$ \\
\hline Hispanic & 8 & $3 \%$ \\
\hline \multicolumn{3}{|l|}{ Insurance } \\
\hline Private & 194 & $65 \%$ \\
\hline Medicare & 85 & $29 \%$ \\
\hline Other & 19 & $6 \%$ \\
\hline Primary care physician access* & 280 & $94 \%$ \\
\hline \multicolumn{3}{|l|}{ Comorbidities } \\
\hline Coronary artery diseaset & 26 & $9 \%$ \\
\hline Congestive heart failure & 12 & $4 \%$ \\
\hline Lung disease $¥$ & 48 & $16 \%$ \\
\hline Asthma & 25 & $8 \%$ \\
\hline Chronic obstructive pulmonary disease & 14 & $5 \%$ \\
\hline Other & 14 & $5 \%$ \\
\hline Malignancy§ & 107 & $36 \%$ \\
\hline Active/palliative & 54 & $18 \%$ \\
\hline Inactive & 50 & $17 \%$ \\
\hline Status unknown & 3 & $1 \%$ \\
\hline Renal insufficiency or failuref & 8 & $3 \%$ \\
\hline Cerebrovascular disease $^{\star *}$ & 20 & $7 \%$ \\
\hline \multicolumn{3}{|l|}{ Disposition } \\
\hline Floor admission & 250 & $84 \%$ \\
\hline Intensive care unit admission & 24 & $8 \%$ \\
\hline ED observation unit & 23 & $8 \%$ \\
\hline Discharged from the ED & 1 & $0.3 \%$ \\
\hline \multicolumn{3}{|c|}{$\begin{array}{l}\text { *Primary care physician access is defined as having a primary care physician listed by } \\
\text { name in our electronic medical record. This includes physicians not affiliated with our } \\
\text { hospital system, but does not imply the availability of rapid follow-up. } \\
\text { tCoronary artery disease includes any history of myocardial infarction, angina, } \\
\text { coronary artery stenting or bypass surgery. } \\
\text { AAsthma, COPD and other lung disease are not mutually exclusive. } \\
\text { SActive malignancy includes any cancer that is being actively treated or palliated, and } \\
\text { metastatic disease. Inactive cancer includes a prior history of cancer that is not } \\
\text { actively being treated or palliated. } \\
\text { IRenal insufficiency or failure includes renal insufficiency, renal failure or } \\
\text { haemodialysis. } \\
{ }^{*} \text { Cerebrovascular disease includes any history of ischaemic or haemorrhagic stroke } \\
\text { or transient ischaemic attack. } \\
\text { ED, emergency department. }\end{array}$} \\
\hline
\end{tabular}

was diagnosed prior to admission to an ED observation unit in $21 / 23$ (91\%). The median hospital length of stay was 3 days (25$75 \%, 1-5$ days) with 87 (29\%) patients in the hospital on day 5. Thirty-day follow-up was successful for 291 (98\%) patients. Of the seven patients without follow-up, six had data in our medical record confirming they were alive 30 days after enrolment.

With regards to our primary outcome, 101 (34\%) patients clinically deteriorated or required a hospital-based intervention within 5 days of PE, whereas 197 (66\%) did not (table 3). Several patients were classified as having clinical deteriorated based on more than one criterion. The most common clinical deterioration events were hypoxaemia/need for respiratory support and hypotension.

Twenty-seven (9\%) patients suffered a severe clinical deterioration or required a major intervention within 5 days of PE diagnosis, including positive pressure ventilation/endotracheal intubation $(n=18 \quad[6 \%])$; ventricular tachycardia/fibrillation $(n=2[0.7 \%])$, vasopressor therapy $(n=1[0.3 \%])$, thrombolysis/ thrombectomy $(n=10[3 \%])$ and death $(n=1[0.3 \%])$.

Seven $(2 \%)$ patients developed bleeding related to anticoagulation within 5 days of $\mathrm{PE}$ diagnosis, including gastrointestinal $(n=2,29 \%)$, intracranial $(n=1,14 \%)$, other bleeding requiring transfusion $(n=1,14 \%)$ and $3(43 \%)$ patients sought care for bleeding after discharge, though the location of this bleeding was not confirmed.

Within 30 days, 12 (4\%) patients died, 10 from end-stage malignancy with no evidence that PE hastened death and 2 from end-stage interstitial pulmonary fibrosis.

\section{Factors associated with clinical deterioration}

Factors associated with our outcomes on univariate analysis are highlighted in table 4. Among the 101 patients with our primary outcome, echocardiography or lower extremity ultrasound identified two who had normal values for biomarkers, oximetry and vital signs. On multivariable analysis, factors independently associated with our primary outcome were lowest systolic blood pressure in the ED $<90 \mathrm{~mm} \mathrm{Hg}(\mathrm{OR}=6.9$ (95\% CI 2.2 to 21.9), $\mathrm{p}=0.001)$, lowest oxygen saturation in the ED $<95 \%(\mathrm{OR}=3.6(95 \% \mathrm{CI} 2.0$ to 6.2$), \mathrm{p}<0.001)$, history of coronary artery disease $(\mathrm{OR}=3.8(95 \% \mathrm{CI} 1.5$ to 9.6$), \mathrm{p}=0.004)$, residual DVT $(\mathrm{OR}=2.4(95 \% \mathrm{CI} 1.3$ to 4.4$), \mathrm{p}=0.006)$ and right heart strain on echocardiogram $(\mathrm{OR}=3.4(95 \% \mathrm{CI} 1.7$ to 6.9), $\mathrm{p}<0.001)$. We also ran our model excluding right heart strain on echocardiogram, and results were similar (data not shown).

Factors associated with severe outcomes were systolic blood pressure $<90 \mathrm{~mm} \mathrm{Hg}$ in the $\mathrm{ED}(\mathrm{OR}=4.2(95 \% \mathrm{CI} 1.3$ to 13.1), $\mathrm{p}=0.015)$, elevated NT-proBNP $(\mathrm{OR}=3.4$ (95\% CI 1.1 to 10.1$), p=0.027)$ and right heart strain on echocardiogram $(\mathrm{OR}=5.6$ (95\% CI 2.2 to 13.9), $\mathrm{p}<0.001)$. Removing right heart strain on echocardiogram from the model, systolic blood pressure $<90 \mathrm{~mm} \mathrm{Hg}$ in the $\mathrm{ED}(\mathrm{OR}=4.6(95 \% \mathrm{CI} 1.5$ to 14.0), $\mathrm{p}=0.008)$, elevated NT-proBNP $(\mathrm{OR}=5.7$ (95\% CI 2.0 to 16.0$), \mathrm{p}<0.001)$ and $\mathrm{PE}$ in a central location $(\mathrm{OR}=3.6(95 \%$ CI 1.4 to 9.1$), p=0.008)$ were associated with severe outcomes.

Factors associated with 30-day all-cause mortality were active malignancy (OR 24.2 (95\% CI 5.0 to 116.6$), \mathrm{p}<0.001)$ and history of congestive heart failure (OR 16.8 (95\% CI 2.0 to 139.3), $\mathrm{p}=0.009$ ). Right heart strain on echocardiogram was not associated with 30-day all-cause mortality.

Including major bleeding events (in hospital or on follow-up) in our primary outcome did not change our results as all patients with bleeding met at least one other outcome criteria (data not shown).

\section{Analysis of CDRs}

The sensitivity all CDRs was moderate, with the PESI and sPESI being more sensitive ( $71 \%$ and $80 \%$, respectively) and the Geneva Prognostic Rule being more specific (84\%) for our primary outcome (table 5). Areas under the ROC curve (AUC) for the primary outcome were PESI $=0.69$, sPESI $=0.69$ and Geneva Prognostic Rule $=0.65$. By comparison, the model using our predictor variables had an AUC of 0.77 for our primary outcome, and our predictive model had a sensitivity of $86 \%$ and a NPV of $88 \%$ using a predictive probability of 0.14 as the cut-off. For severe outcomes, the AUC were PESI=0.68, sPESI $=0.67$ and Geneva Prognostic Rule $=0.61$. For 30-day allcause mortality, the AUC were PESI $=0.84$, sPESI $=0.82$ and Geneva Prognostic Rule $=0.78$. By comparison, our model using 
Table 3 Adverse clinical events occurring within 5 days of PE diagnosis

\begin{tabular}{|c|c|c|c|c|c|c|c|}
\hline Outcome & Overall & Day 0 & Day 1 & Day 2 & Day 3 & Day 4 & Day 5 \\
\hline In hospital & $n=298$ & $\mathrm{n}=298$ & $\mathrm{n}=275$ & $n=211$ & $n=153$ & $\mathrm{n}=113$ & $n=87$ \\
\hline Recurrent PE* & $6(2 \%)$ & $0(0 \%)$ & $1(0.4 \%)$ & $0(0 \%)$ & $0(0 \%)$ & $1(0.9 \%)$ & $0(0 \%)$ \\
\hline Hypotension & $35(12 \%)$ & $16(5 \%)$ & $19(7 \%)$ & $8(4 \%)$ & $8(5 \%)$ & $7(6 \%)$ & $6(7 \%)$ \\
\hline Hypoxaemia or need for respiratory support & $61(20 \%)$ & $42(14 \%)$ & $40(15 \%)$ & $31(15 \%)$ & $29(19 \%)$ & $16(14 \%)$ & $16(18 \%)$ \\
\hline Endotracheal intubation or positive pressure ventilationt & $18(6 \%)$ & $13(4 \%)$ & $10(4 \%)$ & $9(4 \%)$ & $5(3 \%)$ & $3(3 \%)$ & $3(3 \%)$ \\
\hline Thrombolysis/thrombectomy & $10(3 \%)$ & $4(1 \%)$ & $6(2 \%)$ & $0(0 \%)$ & $0(0 \%)$ & $0(0 \%)$ & $0(0 \%)$ \\
\hline Vasopressor use & $1(0.3 \%)$ & $0(0 \%)$ & $1(0.4 \%)$ & $0(0 \%)$ & $0(0 \%)$ & $0(0 \%)$ & $0(0 \%)$ \\
\hline Advanced cardiac life support (ACLS) measures & $0(0 \%)$ & $0(0 \%)$ & $0(0 \%)$ & $0(0 \%)$ & $0(0 \%)$ & $0(0 \%)$ & $0(0 \%)$ \\
\hline New dysrhythmia & $12(4 \%)$ & $0(0 \%)$ & $6(2 \%)$ & $5(2 \%)$ & $3(2 \%)$ & $0(0 \%)$ & $0(0 \%)$ \\
\hline New unstable Dysrhythmiał & $2(0.7 \%)$ & $0(0 \%)$ & $1(0.4 \%)$ & $0(0 \%)$ & $1(0.7 \%)$ & $0(0 \%)$ & $0(0 \%)$ \\
\hline Major bleeding & $7(2 \%)$ & $2(0.7 \%)$ & $0(0 \%)$ & $1(0.5 \%)$ & $1(0.7 \%)$ & $0(0.0 \%)$ & $0(0 \%)$ \\
\hline Deathף & $1(0.3 \%)$ & $0(0 \%)$ & $0(0 \%)$ & $0(0 \%)$ & $0(0 \%)$ & $1(0.9 \%)$ & $0(0 \%)$ \\
\hline
\end{tabular}

In hospital includes patients who were still in the hospital for their index admission. Day 0 includes events occurring $24 \mathrm{~h}$ after the patient left the ED, but before the start of the next calendar day. Events occurring on successive days in the same patient are noted as occurring on each day to give a sense of the continued need for hospitalisation, but only counted once in the overall number of events.

${ }^{*}$ Two recurrent PE were documented in the first 5 days of the index hospitalisation. Four additional patients returned to an ED within 5 days for symptoms related to recurrent PE and were classified among overall recurrent PE.

tIn the primary analysis, patients requiring endotracheal intubation or positive pressure ventilation were included in the analysis of respiratory support and patients with unstable dysrhythmias were considered in the analysis of all dysrhythmias. In the analysis of severe outcomes, these were considered separately.

‡Dysrhythmia includes atrial fibrillation, atrial flutter, ventricular tachycardia, ventricular fibrillation or reentrant supraventricular tachycardia not present on subject's ED electrocardiogram. Unstable dysrhythmia includes ventricular tachycardia or ventricular fibrillation.

§Four major bleeding episodes occurred during the first 5 days of the index hospitalisation. Three additional patients returned to an ED within 5 days for bleeding and were classified among overall major bleeding.

IOne patient died while in hospital during the index hospitalisation. Two additional patients were confirmed to have died on 5-day telephone follow-up and are included among overall 5-day deaths.

ED, emergency department.

systolic blood pressure $<90 \mathrm{~mm} \mathrm{Hg}$ in the ED, elevated NT-proBNP and right heart strain on echocardiogram had an AUC of 0.83 , and the model had a sensitivity of $93 \%$ and a NPV of $99 \%$ using a predictive probability of 0.06 as the cut-off.

We performed a secondary analysis, adjusting our definition of low risk to include PESI category I only. Test characteristics for our primary outcome were sensitivity $85 \%$ (95\% CI 77\% to 91\%), specificity $37 \%$ (95\% CI $30 \%$ to $44 \%$ ), PPV $41 \%(95 \%$ CI $34 \%$ to $48 \%$ ) and NPV $83 \%$ (95\% CI 73\% to 90\%).

In the subanalysis of patients with a shock index $<1 \quad(n=233)$ in the ED, sensitivity and NPV were lower for all CDRs. Results were similar for severe outcomes (data not shown).

\section{DISCUSSION}

The ability to assess patients' risk of short-term clinical deterioration after PE has gained importance in recent years. Low-risk patients may be eligible for outpatient treatment with heparin or novel oral anticoagulants. ${ }^{15} 25$ Meta-analyses, systematic reviews and a large clinical trial support the safety of this approach. ${ }^{152627}$ Piran et al ${ }^{26}$ found that selected patients with PE treated as outpatients had low rates of recurrent venous thromboembolism (VTE) (1.47\%), fatal PE (0.47\%) and major bleeding (0.81\%), and Vinson et $a l^{28}$ found that outpatient treatment was associated with low 90-day VTE-related mortality. Conversely, high-risk patients with PE may benefit from intravenous or catheter-directed thrombolysis. Determining whether outpatient treatment or aggressive intervention is appropriate for a patient with $\mathrm{PE}$ is now a critical decision in emergency medicine.

In this study, we provide detailed prospective data on the incidence of clinical deterioration and the need for hospital-based interventions related to $\mathrm{PE}$, occurring shortly after diagnosis. Our primary outcome was broad-based and designed to capture the spectrum of events that might justify hospitalisation. Unlike prior studies, we only studied outcomes occurring during a typical inpatient admission. Even with our broad definition, we found that most patients (66\%) suffer no clinical deterioration and require no hospital-based intervention within 5 days of $\mathrm{PE}$ diagnosis. Our results are consistent with previous work and suggest that many patients with PE may not benefit from inpatient hospitalisation. ${ }^{2} 1522$

We identified several factors associated with clinical deterioration after PE, including abnormal vital signs, the presence of right heart strain on echocardiogram, residual DVT and elevated biomarkers. These factors have face validity and have been shown to be associated with clinical deterioration in previous

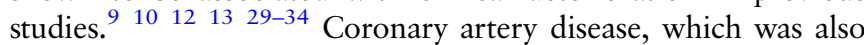
associated with our primary outcome, may make patients less able to withstand increased pulmonary artery pressure. This will require further exploration.

Interestingly, we found that factors associated with 5-day clinical deterioration were generally different than factors associated with 30-day all-cause mortality. This finding was true on univariate and multivariable analysis, and for our primary and severe outcomes. Factors associated with 30-day all-cause mortality included malignancy and a history of congestive heart failure, suggesting that 30 -day mortality is often related to preexisting illness, rather than the acute PE. While we acknowledge that pre-existing illness is important to consider, future studies should emphasise outcomes directly related to the PE.

We found published CDRs to be moderately sensitive for our outcomes, but highly sensitive for 30-day mortality. This may be explained by the fact that the CDRs we examined all include malignancy; the cause of death for 10/12 (83\%) patients in our study. The PESI and sPESI also include chronic cardiopulmonary disease, which was the cause of death for the remaining two patients.

\section{Limitations}

We used complimentary methods to achieve consecutive enrolment, but when we reviewed radiology records to identify 
Table 4 Univariate associations with clinical deterioration or need for hospital-based intervention within 5 days of PE diagnosis

\begin{tabular}{|c|c|c|c|c|c|c|c|c|c|c|c|}
\hline \multirow[b]{2}{*}{ Variable } & \multirow[b]{2}{*}{$\begin{array}{l}\text { \# with } \\
\text { trait }\end{array}$} & \multirow[b]{2}{*}{$\begin{array}{l}\% \text { with } \\
\text { trait }\end{array}$} & \multicolumn{3}{|l|}{ Primary outcome } & \multicolumn{3}{|l|}{ Severe outcome } & \multicolumn{3}{|l|}{ 30-day mortality } \\
\hline & & & $\begin{array}{l}\% \text { of patients } \\
\text { without trait with } \\
\text { outcome }\end{array}$ & $\begin{array}{l}\% \text { of patients } \\
\text { with trait with } \\
\text { outcome }\end{array}$ & $\mathrm{p}$-Value & $\begin{array}{l}\% \text { of patients } \\
\text { without trait with } \\
\text { outcome }\end{array}$ & $\begin{array}{l}\% \text { of patients } \\
\text { with trait with } \\
\text { outcome }\end{array}$ & $\mathrm{p}$-Value & $\begin{array}{l}\% \text { of patients } \\
\text { without trait with } \\
\text { outcome }\end{array}$ & $\begin{array}{l}\% \text { of patients } \\
\text { with trait with } \\
\text { outcome }\end{array}$ & p-Value \\
\hline Age $\geq 65$ years & 117 & 39 & 28 & 44 & 0.004 & 8 & 11 & 0.321 & 2 & 7 & 0.045 \\
\hline Highest HR >100 bpm & 105 & 35 & 30 & 41 & 0.058 & 7 & 12 & 0.141 & 4 & 5 & 0.641 \\
\hline Lowest SBP $<90 \mathrm{~mm} \mathrm{Hg}$ & 20 & 7 & 31 & 75 & $<0.001$ & 7 & 35 & $<0.001$ & 4 & 10 & 0.161 \\
\hline Highest RR >20 BrPM & 91 & 31 & 27 & 49 & $<0.001$ & 6 & 15 & 0.012 & 3 & 7 & 0.130 \\
\hline Lowest $\mathrm{SaO}_{2}<95 \%$ & 105 & 35 & 24 & 52 & $<0.001$ & 6 & 15 & 0.006 & 3 & 7 & 0.084 \\
\hline White race & 268 & 90 & 27 & 35 & 0.378 & 10 & 9 & 0.850 & 0 & 4 & 0.236 \\
\hline Coronary artery disease & 26 & 9 & 31 & 62 & 0.002 & 9 & 8 & 0.799 & 4 & 8 & 0.322 \\
\hline Congestive heart failure & 12 & 4 & 33 & 50 & 0.229 & 9 & 8 & 0.929 & 4 & 17 & 0.023 \\
\hline Chronic lung disease & 48 & 16 & 32 & 42 & 0.214 & 8 & 15 & 0.146 & 3 & 10 & 0.014 \\
\hline Malignancy & 107 & 36 & 30 & 40 & 0.086 & 9 & 8 & 0.770 & 1 & 9 & $<0.001$ \\
\hline Malignancy (active) & 54 & 18 & 33 & 37 & 0.590 & 10 & 4 & 0.130 & 1 & 17 & $<0.001$ \\
\hline Chronic renal insufficiency & 8 & 3 & 33 & 50 & 0.329 & 9 & 13 & 0.731 & 4 & 14 & 0.164 \\
\hline Cerebrovascular disease & 20 & 7 & 32 & 55 & 0.039 & 9 & 10 & 0.880 & 4 & 0 & 0.342 \\
\hline D-dimer $\geq 3000 \mathrm{mcg} / \mathrm{mL}$ & 133 & 45 & 30 & 39 & 0.088 & 7 & 11 & 0.231 & 4 & 5 & 0.693 \\
\hline Troponin- $\mathrm{T} \geq 0.1 \mathrm{ng} / \mathrm{mL}$ & 12 & 4 & 33 & 50 & 0.229 & 8 & 25 & 0.050 & 4 & 8 & 0.441 \\
\hline NT-proBNP $\geq 200 \mathrm{pg} / \mathrm{mL}$ & 128 & 43 & 25 & 46 & $<0.001$ & 3 & 17 & $<0.001$ & 2 & 6 & 0.087 \\
\hline PE central ${ }^{*}$ & 139 & 47 & 31 & 37 & 0.230 & 4 & 14 & 0.003 & 5 & 3 & 0.340 \\
\hline PE multiple & 203 & 68 & 27 & 37 & 0.104 & 11 & 8 & 0.546 & 4 & 4 & 0.898 \\
\hline Residual DVT & 74 & 25 & 29 & 47 & 0.005 & 8 & 14 & 0.124 & 4 & 5 & 0.472 \\
\hline Right heart strain on echocardiogramt & 52 & 17 & 28 & 63 & $<0.001$ & 4 & 31 & $<0.001$ & 4 & 4 & 0.962 \\
\hline
\end{tabular}

Significant associations are highlighted.

${ }^{*}$ Central PE is defined as any clot proximal to the segmental pulmonary arteries.

tRight heart strain on echocardiogram includes any finding of right ventricular hypertrophy, right ventricular dilatation or bowing of the intraventricular septum towards the left ventricle.

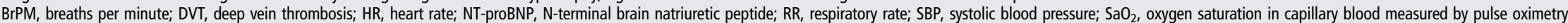


Table 5 Test characteristics of clinical decision rules

\begin{tabular}{|c|c|c|c|c|c|c|}
\hline & Sensitivity & Specificity & PPV & NPV & $\operatorname{LR}(+)$ & $\operatorname{LR}(-)$ \\
\hline \multicolumn{7}{|l|}{$\mathrm{PESI}^{*}\left(\right.$ ref. $^{8}$ ) } \\
\hline Primary outcome & $71 \%(61-0.80 \%)$ & $58 \%(51-65 \%)$ & $47 \%(39-55 \%)$ & $80 \%(72-86 \%)$ & $1.71(1.39-2.11)$ & $0.49(0.35-0.68)$ \\
\hline Severe outcome & $78 \%(58-91 \%)$ & $51 \%(45-57 \%)$ & $14 \%(09-20 \%)$ & $96 \%(91-98 \%)$ & $1.58(1.25-2.01)$ & $0.44(0.21-0.89)$ \\
\hline $\begin{array}{l}\text { 30-day mortality } \\
\text { sPESI(ref. }{ }^{12} \text { ) }\end{array}$ & $100 \%(74-100 \%)$ & $51 \%(45-56 \%)$ & $08 \%(04-13 \%)$ & $100 \%(97-100 \%)$ & $2.02(1.80-2.27)$ & - \\
\hline Primary outcome & $80 \%(71-87 \%)$ & $42 \%(35-49 \%)$ & $41 \%(34-49 \%)$ & $80 \%(71-88 \%)$ & $1.37(1.18-1.60)$ & $0.48(0.31-0.73)$ \\
\hline Severe outcome & $81 \%(62-94 \%)$ & $36 \%(30-42 \%)$ & $11 \%(07-16 \%)$ & $95 \%(89-98 \%)$ & 1.27 (1.04-1.55) & $0.52(0.23-1.16)$ \\
\hline $\begin{array}{l}\text { 30-day mortality } \\
\text { Geneva(ref. }{ }^{3} \text { ) }\end{array}$ & $100 \%(74-10 \%)$ & $36 \%(30-42 \%)$ & $06 \%(03-11 \%)$ & $100 \%(96-100 \%)$ & $1.56(1.43-1.70)$ & - \\
\hline Primary outcome & $39 \%(29-49 \%)$ & $84 \%(78-89 \%)$ & $55 \%(43-67 \%)$ & $73 \%(66-78 \%)$ & $2.38(1.59-3.55)$ & $0.73(0.62-0.87)$ \\
\hline Severe outcome & $44 \%(25-65 \%)$ & $78 \%(73-83 \%)$ & $17 \%(09-28 \%)$ & $93 \%(88-96 \%)$ & $2.04(1.27-3.29)$ & $0.71(0.50-1.00)$ \\
\hline 30-day mortality & $67 \%(35-90 \%)$ & $78 \%(73-83 \%)$ & $11 \%(05-21 \%)$ & $98 \%(96-100 \%)$ & $3.06(1.94-4.84)$ & $0.43(0.19-0.95)$ \\
\hline
\end{tabular}

patients diagnosed with PE at night, we could not confirm that an ultrasound was performed in a patient suspected of having PE. We may therefore have missed some patients diagnosed by ultrasound alone. Only five $(2 \%)$ enrolled patients were diagnosed by ultrasound alone so we suspect few patients were missed. Informed consent was required, so we could not enrol patients with severely altered mental status, significant hemodynamic instability or endotracheal intubation. Although a substantial number $(n=65(21 \%))$ of enrolled patients had a shock index $\geq 1$, our sample may under-represent severe PE.

To standardise the collection of data, we included test results obtained within $24 \mathrm{~h}$ of PE diagnosis and defined these as being 'available to the emergency physician'. We felt limiting our predictive data to results actually obtained in the ED would introduce unacceptable variability unrelated to the safety of outpatient PE treatment. By including data obtained up to $24 \mathrm{~h}$ after PE diagnosis, our results may also be applicable to an ED/ observation unit stay. However, with the exception of echocardiography, the tests we analysed are rapidly available in most EDs. We therefore believe our results are directly relevant to ED decision making.

We followed patients for clinical deterioration occurring in the hospital and on telephone follow-up, but as some events are more likely to be recognised and reported by patients, we may have missed some clinical deterioration events occurring after discharge. Our 5-day outcomes are different than those for which CDRs were derived, and this likely affected their test characteristics. However, we feel our outcome is directly relevant to the decision to admit or discharge a patient from the ED.

We did not include in our analysis social factors or concurrent illness that might limit the practicality of outpatient treatment, as has been done in other studies. ${ }^{28} 3536$ Finally, while our study suggests that a large proportion of patients might not require hospitalisation, we did not directly assess the safety of outpatient treatment in this study. A management study based on short-term, patient-centred outcomes would be beneficial.

\section{CONCLUSIONS}

Most (66\%) patients suffer no clinical deterioration and require no hospital-based intervention in the first five days after PE. The outpatient treatment of PE is likely safe for a large proportion of patients. Abnormal vital signs, imaging findings and elevated biomarkers are associated with short-term clinical deterioration related to PE. However, existing CDRs are only moderately sensitive for this outcome. Future research focusing on outcomes directly related to $\mathrm{PE}$ is needed to facilitate safe outpatient treatment.

\section{Collaborators Parry, Blair A.}

Contributors CK: conceived the study, obtained funding, collected and analysed data, drafted and edited the manuscript. 10 and PH conceived the study, collected data and edited the manuscript. JKT obtained funding, analysed the data and edited the manuscript. PM and FH collected and analysed data, drafted and edited the manuscript. YC analysed data and edited the manuscript.

Funding This work was funded by a grant from the Harvard Milton Fund. The funding agency had no role in the design of the study, analysis or writing the manuscript.

\section{Competing interests None.}

Patient consent Obtained.

Ethics approval Human Research Committee, Partners HealthCare.

Provenance and peer review Not commissioned; externally peer reviewed.

Data sharing statement Requests to collaborate and use data published here will be considered. Data referenced, but not shown will be provided upon request.

\section{REFERENCES}

1 Chan CM, Woods C, Shorr AF. The validation and reproducibility of the pulmonary embolism severity index. J Thromb Haemost 2010;8:1509-14.

2 Squizzato A, Donadini MP, Galli L, et al. Prognostic clinical prediction rules to identify a low-risk pulmonary embolism: a systematic review and meta-analysis. J Thromb Haemost 2012;10:1276-90.

3 Wicki J, Perrier A, Perneger TV, et al. Predicting adverse outcome in patients with acute pulmonary embolism: a risk score. Thromb Haemost 2000;84:548-52.

4 Nendaz MR, Bandelier P, Aujesky D, et al. Validation of a risk score identifying patients with acute pulmonary embolism, who are at low risk of clinical adverse outcome. Thromb Haemost 2004;91:1232-6.

5 Jimenez D, Yusen RD, Otero R, et al. Prognostic models for selecting patients with acute pulmonary embolism for initial outpatient therapy. Chest 2007;132:24-30.

6 Subramaniam RM, Mandrekar J, Blair D, et al. The Geneva prognostic score and mortality in patients diagnosed with pulmonary embolism by CT pulmonary angiogram. J Med Imaging Radiat Oncol 2009;53:361-5.

7 Bova C, Pesavento R, Marchiori A, et al. Risk stratification and outcomes in hemodynamically stable patients with acute pulmonary embolism: a prospective, multicentre, cohort study with three months of follow-up. J Thromb Haemost 2009; 7:938-44. 
8 Aujesky D, Obrosky DS, Stone RA, et al. Derivation and validation of a prognostic model for pulmonary embolism. Am J Respir Crit Care Med 2005;172:1041-6.

9 Aujesky D, Obrosky DS, Stone RA, et al. A prediction rule to identify low-risk patients with pulmonary embolism. Arch Intern Med 2006;166:169-75.

10 Aujesky D, Perrier A, Roy PM, et al. Validation of a clinical prognostic model to identify low-risk patients with pulmonary embolism. J Intern Med 2007;261:597-604

11 Donze J, Le Gal G, Fine MJ, et al. Prospective validation of the Pulmonary Embolism Severity Index. A clinical prognostic model for pulmonary embolism. Thromb Haemost 2008;100:943-8.

12 Jimenez D, Aujesky D, Moores L, et al. Simplification of the pulmonary embolism severity index for prognostication in patients with acute symptomatic pulmonary embolism. Arch Intern Med 2010;170:1383-9.

13 Aujesky D, Roy PM, Le Manach CP, et al. Validation of a model to predict adverse outcomes in patients with pulmonary embolism. Eur Heart J 2006;27:476-81.

14 Jakobsson C, Jimenez D, Gomez V, et al. Validation of a clinical algorithm to identify low-risk patients with pulmonary embolism. J Thromb Haemost 2010;8:1242-7.

15 Aujesky D, Roy PM, Verschuren F, et al. Outpatient versus inpatient treatment for patients with acute pulmonary embolism: an international, open-label, randomised non-inferiority trial. Lancet 2011;378:41-8.

16 Jimenez D, Aujesky D, Moores L, et al. Combinations of prognostic tools for identification of high-risk normotensive patients with acute symptomatic pulmonary embolism. Thorax 2011;66:75-81.

17 Erkens PM, Gandara E, Wells PS, et al. Does the Pulmonary Embolism Severity Index accurately identify low risk patients eligible for outpatient treatment? Thromb Res 2012;129:710-14.

18 Sanchez D, De Miguel J, Sam A, et al. The effects of cause of death classification on prognostic assessment of patients with pulmonary embolism. J Thromb Haemost 2011:9:2201-7.

19 Pollack CV, Schreiber D, Goldhaber SZ, et al. Clinical characteristics, management, and outcomes of patients diagnosed with acute pulmonary embolism in the emergency department: initial report of EMPEROR (Multicenter Emergency Medicine Pulmonary Embolism in the Real World Registry). J Am Coll Cardiol 2011; 57:700-6.

20 Kabrhel C, Sacco W, Liu S, et al. Outcomes considered most important by emergency physicians when determining disposition of patients with pulmonary embolism. Int J Emerg Med 2010;3:239-64.

21 von Elm E, Altman DG, Egger M, et al. The Strengthening the Reporting of Observational Studies in Epidemiology (STROBE) statement: guidelines for reporting observational studies. PLoS Med 2007:4:e296.
22 Hariharan P, Takayesu JK, Kabrhel C. Association between the Pulmonary Embolism Severity Index (PESI) and short-term clinical deterioration. Thromb Haemost 2011:105:706-11.

23 Aujesky D, Stone RA, Kim S, et al. Length of hospital stay and postdischarge mortality in patients with pulmonary embolism: a statewide perspective. Arch Intern Med 2008;168:706-12.

24 Kline JA, Mitchell AM, Runyon MS, et al. Electronic medical record review as a surrogate to telephone follow-up to establish outcome for diagnostic research studies in the emergency department. Acad Emerg Med 2005;12:1127-33.

25 Buller HR, Prins $\mathrm{MH}$, Lensin $\mathrm{AW}$, et al. Oral rivaroxaban for the treatment of symptomatic pulmonary embolism. N Engl J Med 2012;366:1287-97.

26 Piran S, Le Gal G, Wells PS, et al. Outpatient treatment of symptomatic pulmonary embolism: a systematic review and meta-analysis. Thromb Res 2013;132: 515-19.

27 Barra SN, Paiva L, Providencia R, et al. A review on state-of-the-art data regarding safe early discharge following admission for pulmonary embolism: what do we know? Clinical Cardiology 2013;36:507-15.

28 Vinson DR, Zehtabchi S, Yealy DM. Can selected patients with newly diagnosed pulmonary embolism be safely treated without hospitalization? A systematic review. Ann Emerg Med 2012;60:651-62 e4.

29 Giannitsis E, Muller-Bardorff M, Kurowski V, et al. Independent prognostic value of cardiac troponin $\mathrm{T}$ in patients with confirmed pulmonary embolism. Circulation 2000;102:211-17.

30 Janata $\mathrm{K}$, Holzer $\mathrm{M}$, Laggner $\mathrm{AN}$, et al. Cardiac troponin $\mathrm{T}$ in the severity assessment of patients with pulmonary embolism: cohort study. BMJ 2003;326:312-13.

31 Kucher N, Printzen G, Doernhoefer T, et al. Low pro-brain natriuretic peptide levels predict benign clinical outcome in acute pulmonary embolism. Circulation 2003;107:1576-8.

32 Kucher N, Printzen G, Goldhaber SZ. Prognostic role of brain natriuretic peptide in acute pulmonary embolism. Circulation 2003;107:2545-7.

33 La Vecchia L, Ottani F, Favero L, et al. Increased cardiac troponin I on admission predicts in-hospital mortality in acute pulmonary embolism. Heart 2004;90: 633-7.

34 ten Wolde M, Tulevski II, Mulder JW, et al. Brain natriuretic peptide as a predictor of adverse outcome in patients with pulmonary embolism. Circulation 2003;107:2082-4.

35 Zondag W, Mos IC, Creemers-Schild D, et al. Outpatient treatment in patients with acute pulmonary embolism: the Hestia Study. J Thromb Haemost 2011;9:1500-7.

36 Zondag W, Kooiman J, Klok FA, et al. Outpatient versus inpatient treatment in patients with pulmonary embolism: a meta-analysis. Eur Respir J 2013:42:134-44. 